\title{
LAS TIC Y LAS CULTURAS MINORITARIAS EN UN MUNDO GLOBAL.
}

Resumen. Las culturas minoritarias, sus lenguas y tradiciones se vuelven más minoritarias y su aliento vital se debilita a medida que la globalización las sitúa dentro de un contexto mucho más amplio. La aparición de las Nuevas Tecnologías (NN.TT.) e Internet como base de las mismas ha supuesto una nueva discriminación entre los que tienen acceso a ellas y los que no. Las culturas minoritarias lo son por haber sido doblegadas por otra dominante y por ello, a menudo padecen males más acuciantes que la pérdida de su identidad (desempleo, pobreza, exclusión social, etc), lo cual hace aún más complicado reafirmar sus raíces cuando hacerlo significa continuar en condiciones de vida inferiores a las que uno tendría integrándose en la nueva cultura dominante. En este artículo, pretendemos mostrar la importancia de las NN.TT. y las enormes posibilidades que ofrece para la recuperación de estas culturas amenazadas, integrándolas en el mundo de Internet, dándoles una voz y un lugar donde reunirse, comunicarse y enriquecer el patrimonio universal con su visión particular y única del mundo.

Palabras claves: inclusión digital, brecha digital, Web 2.0, culturas minoritarias, lenguas amenazadas.

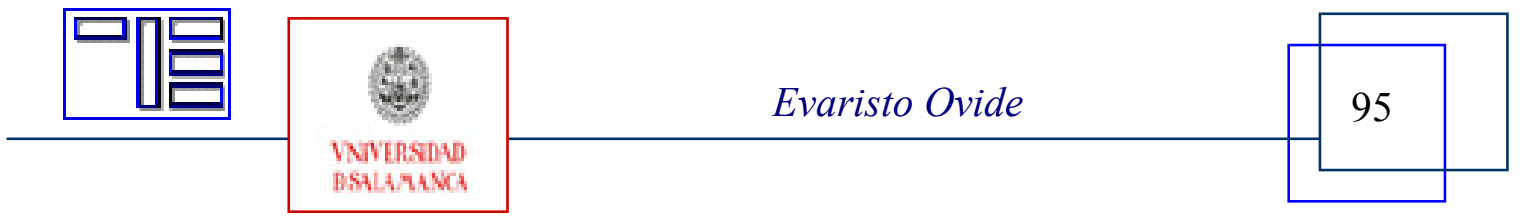


Revista Electrónica Teoría de la Educación.

Educación y Cultura en la Sociedad de la Información.

http://www.usal.es/teoriaeducacion

Vol. 9. No 2. Mayo 2008

\section{ICT AND MINORITY CULTURES IN A GLOBAL WORLD.}

Abstract. Minority cultures, their languages and traditions become even more of a minority and their vital breath fades out as globalization places them in a much wider context. The appearance of the Information and Communication Technologies (ICT), and the Internet as a backbone for them, has created a new discrimination between those who have access to them and those who do not. Minority cultures are defined by the fact that they have been overcome by a dominant culture; therefore, they often suffer more urgent evils than their identity loss (unemployment, poverty, social discrimination, etc.). This makes it also more difficult for them to reafirm their roots, since doing so means that they will be living at a lower standard than if they integrated in the dominant culture. In this article we intend to show the importance of the ICT and the enormous possibilities they offer to the recuperation of these endangered cultures, integrating them in the Internet world, giving them a voice and a space to meet, to communicate and to enrich the world heritage with their particular and unique vision of the world.

Key words: digital inclusion, digital divide, Web 2.0, minority cultures, endangered language.

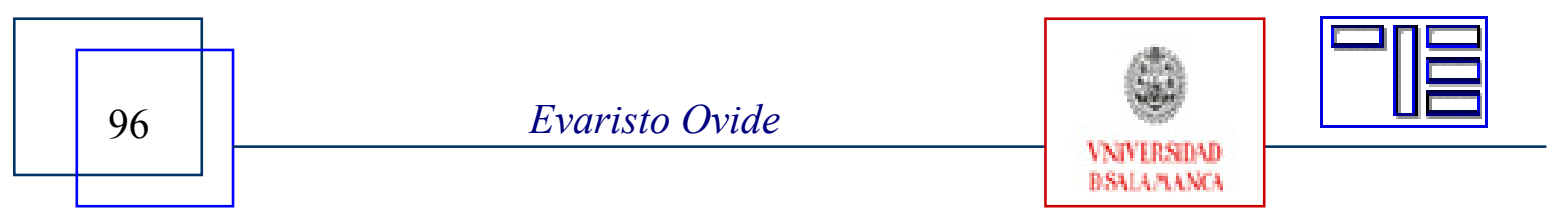




\section{LES NTIC ET LES CULTURES MINORITAIRES DANS UN MONDE GLOBAL.}

Sommaire. Les cultures minoritaires, leurs langues et leurs traditions deviennent encore plus minoritaires et leur souffle vital s'estompe à mesure que la mondialisation les place dans un contexte beaucoup plus grand. L'apparition des Nouvelles Technologies de l'Information et des Communications (NTIC), et l'Internet en tant que dorsale pour eux, a créé une nouvelle discrimination entre ceux qui ont accès a eux et ceux qui n'en ont pas. Les cultures minoritaires sont dans cette situation parce qu'elles ont été surmontées par une culture dominante et par conséquent, ils souffrent souvent des maux plus urgent que la perte de leur identité (le chômage, la pauvreté, la discrimination sociale, etc.) Ça rend encore plus difficile pour eux de reafirm leurs racines, car le faire signifie qu'ils seront vivant à un niveau plus faible que si elles intégrées dans la culture dominante. Dans cet article, nous avons l'intention de montrer l'importance des NTIC et des immenses possibilités qu'elles offrent à la récupération de ces cultures menacées, en les intégrant dans le monde d'Internet, en leur donnant une voix et un espace pour se rencontrer, pour se communiquer et pour enrichir le monde avec leur patrimoine particulier et unique vision du monde.

Mots-clés: l'inclusion numérique, fracture numérique, Web 2.0, les cultures minoritaires, les langues en péril.

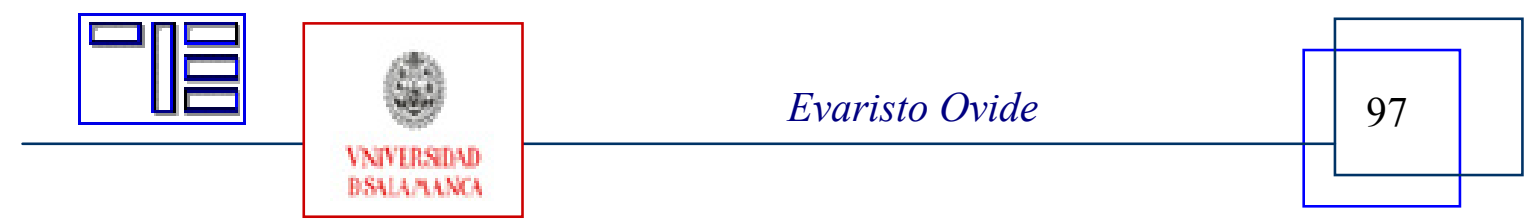


Revista Electrónica Teoría de la Educación.

Educación y Cultura en la Sociedad de la Información.

http://www.usal.es/teoriaeducacion

Vol. 9. No 2. Mayo 2008

\section{LAS TIC Y LAS CULTURAS MINORITARIAS EN UN MUNDO GLOBAL.}

"Lo que se llama "globalización" es una forma específica de integración internacional, diseñada y creada para propósitos concretos. Hay muchas alternativas posibles, pero esta forma particular está orientada hacia los intereses del poder privado, creando corporaciones e instituciones financieras estrechamente unidas a poderosos estados".

(Noam Chomsky, Washington Post, 16-5-2000)

Evaristo Ovide

evaristo_ovide@usal.es

Universidad de Salamanca (España).

\section{1.- INTRODUCCIÓN.}

Si bien la globalización tiene, en mayor o menor grado, repercusiones en casi todos los aspectos de nuestras vidas (político, económico, laboral, social, cultural, etc), nos centraremos en este artículo en el aspecto cultural, y más concretamente, y como uno de los elementos más representativos de una cultura, en el aspecto lingüístico y su situación dentro de este proceso de globalización.

Las Nuevas Tecnologías se han convertido como un instrumento decisivo para la consolidación y expansión del proceso de globalización. Las multinacionales pueden operar a tiempo real entre sus distintas sedes en el mundo, las empresas de un país pueden fabricar en otro y vender a muchos otros a través de Internet, los datos viajan por Internet de un lado del mundo [desarrollado] al otro en cuestión de instantes... Internet se convierte en el Nuevo Mundo, casi virgen, lleno de potencial y de recursos. Es un mundo que las grandes corporaciones, en combinación con los gobiernos, intentan dominar y colonizar para ganar más beneficios y controlar más al ciudadano, bien con patentes de software, con licencias restrictivas de uso de programas, con cuotas injustificadas que presuponen la inclinación criminal del usuario (como el canon de la Sociedad General de Autores Españoles ${ }^{1}$ ) o mediante sistemas que impidan compartir el conocimiento y la cultura. Pero al mismo tiempo, y estas son las posibilidades sobre las que queremos tratar en este artículo, es un espacio donde las voces de los distintos lugares del mundo se unen para producir iniciativas comunes que desafían el imperio de las corporaciones, sin buscar más beneficio que el bien común y desinteresado, como el movimiento del software libre ${ }^{2}$ o la Wikipedia ${ }^{3}$, por ejemplo, el éxito de las cuales demuestra la capacidad de las Nuevas Tecnologías para defender intereses distintos a los de las grandes corporaciones partiendo de mínimos presupuestos y trabajando en comunidad.

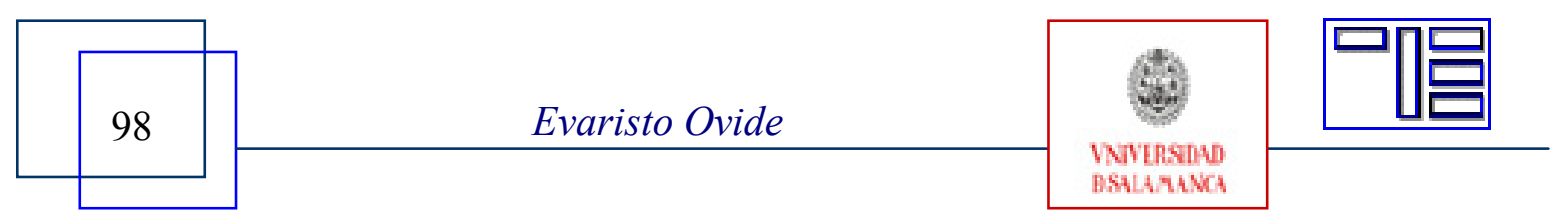




\section{2.- LENGUAS Y CULTURAS AMENAZADAS ¿POR QUÉ SALVARLAS?}

El propósito de este artículo es poner de relieve la importancia de las NN.TT. en la recuperación y promoción de lenguas y culturas en peligro de extinción. Sería difícil transmitir la importancia de las NN.TT. como medio si no tenemos clara la importancia del fin, por lo que consideramos relevante dedicar unas líneas a exponer la situación en este campo y las razones por las que creemos que este fin tiene una gran importancia.

Se calcula que hay en el mundo unas 6.000 lenguas. De ese número, la inmensa mayoría (un $95 \%$ ) son habladas por solo un $5 \%$ de la población mundial. O dicho de otra forma, el 95\% de la Humanidad habla alguna de las lenguas incluidas en solo un 5\% del total (Bernard, 1996, p. 142). En este próximo siglo, se calcula que la mitad de esas lenguas desaparecerán, es decir, cada dos semanas, una lengua desaparece (Crystal, 2000, p. 1). Todos somos conscientes del gran peligro que corre la biodiversidad en nuestro planeta y vemos como una catástrofe que recibe una gran publicidad el hecho de que se considere que un $2 \%$ de la flora y fauna del planeta está en serio peligro de extinción. Sin embargo, el $50 \%$ de todas las lenguas del mundo está en peligro de extinción y no recibe apenas atención en los medios (Crystal, 2006, p. 1). Esto se debe en gran parte a que las organizaciones en defensa de la biodiversidad llevan haciendo campañas y obteniendo fondos durante unos cincuenta años, mientras que la defensa de las lenguas amenazadas apenas tiene diez años (no fue hasta 1995 que la Unesco publicó el Libro Rojo de las Lenguas Amenazadas; ${ }^{4}$ a finales de los noventa fue cuando se publicaron libros y antologías centrándose en el problema y solo en los últimos años la Unesco comenzó a organizar conferencias sobre el tema y considerarlo como un problema global a nivel mundial).

La importancia de una lengua no se basa exclusivamente en el poder comunicar un mensaje $\mathrm{X}$ a un oyente $\mathrm{Y}$. Si la comunicación con el mayor número de hablantes fuera la única base para la existencia de una lengua, en la América hispanoparlante todas las lenguas indígenas habrían desaparecido en favor de la lengua castellana y en España las seis lenguas que aún hoy existen habrían hecho lo mismo hace siglos. Así, tendremos que plantear otra razón que haga que las comunidades se aferren a sus lenguas a pesar del hecho de que solo les sirva para un reducido número de situaciones y de que esos mismos hablantes también hablen la lengua dominante. Podríamos resumir ese causa en dos razones: desde el punto de vista comunicativo, la lengua de los nativos del lugar siempre será mucho más precisa y eficaz para describir la realidad que una lengua que procede de una realidad distinta ${ }^{5}$. Por otro lado, las lenguas tienen otra función: la de identificación cultural y étnica.

Las lenguas son probablemente la seña de identidad más importante de una cultura, ya que codifica la realidad y la percepción del mundo de sus hablantes. El grupo de expertos internacionales para las lenguas amenazadas de la Unesco (Unesco, 2003, p. 3), afirman que "La extinción de una lengua resulta en la pérdida irrecuperable de un conocimiento cultural, ecológico e histórico único. Cada lengua es la expresión de una experiencia humana única. Así, el conocimiento de una sola lengua puede ser la clave

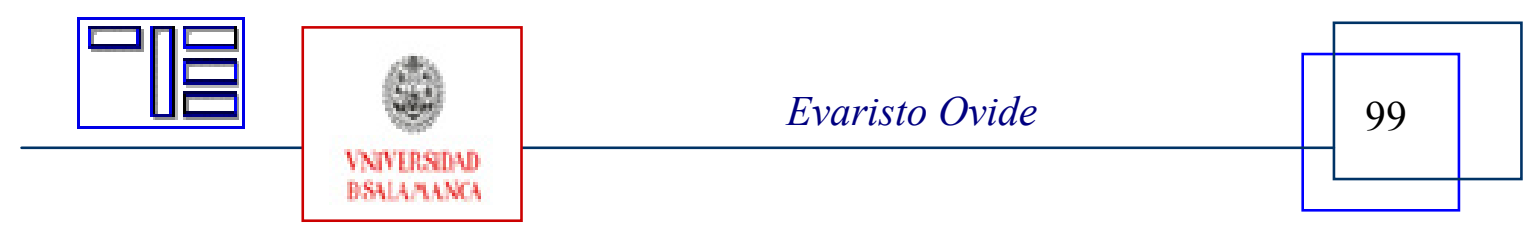


Revista Electrónica Teoría de la Educación.

Educación y Cultura en la Sociedad de la Información.

http://www.usal.es/teoriaeducacion

Vol. 9. No 2. Mayo 2008

para resolver problemas fundamentales del futuro". Las lenguas codifican la realidad de una forma única y estrechamente unida al medio donde se desarrolla. Una lengua foránea, al no proceder del mismo ecosistema, orografía, clima, historia, etc, no puede describir la realidad con la misma eficacia que la del lugar, no puede expresar con la misma precisión los sentimientos del pueblo nativo y la expresión de sus ideas de la misma forma que la lengua con la que ellos y sus ancestros codificaron su mundo, de ahí que las lenguas impuestas por las culturas dominantes (español, inglés, portugués o francés) siempre acaban adaptándose y separándose de la variedad original (hasta llegar a producir, en algunos casos lenguas nuevas por contacto, las denominadas lenguas criollas) en un intento de poder describir lo más precisamente posible la realidad que les rodea. Los significados de los topónimos pierden su sentido cuando la nueva lengua los cambia a sus reglas fonológicas o morfológicas ${ }^{6}$, los nombres de las plantas indicativos de sus propiedades, origen u otro detalle desaparece en un nombre impuesto que elimina ese conocimiento, la mitología del lugar desaparece cuando la nueva lengua no pone nombres a conceptos, deidades o sentimientos que no conoce y que acaban desapareciendo por desuso y así, toda la riqueza que englobaba esa lengua se pierde.

Las lenguas y el conocimiento que representaban fueron desapareciendo a lo largo de los siglos por distintas razones (el hitita desapareció en tiempos del Antiguo Testamento junto con su cultura, por ejemplo), al igual que las especies animales y vegetales (los tigres de dientes de sable o los dinosaurios se extinguieron y no lo vemos como algo alarmante). Lo que es preocupante y grave es la velocidad con que el fenómeno está teniendo lugar ahora (una lengua cada dos semanas) ante la imparable globalización y difusión de las lenguas mayoritarias a través de los medios de comunicación, incluido Internet. En la Declaración de Principios de la Cumbre Mundial sobre la Sociedad de la Información de Ginebra se hace mención a la importancia de preservar esta riqueza: "La promoción, la afirmación y preservación de los diversos idiomas e identidades culturales, tal como se consagran en los correspondientes documentos acordados por las Naciones Unidas, incluida la Declaración Universal de la UNESCO sobre la Diversidad Cultural, contribuirán a enriquecer aún más la Sociedad de la Información" (CMSI, 2004, punto 52). Aquí es donde las NN.TT. brindan una gran oportunidad para la recuperación de esta riqueza cultural y lingüística.

\section{3.- PRIMER Y GRAN PROBLEMA: LA "BRECHA DIGITAL"}

El primer problema que encontramos a la hora de sacar las lenguas y culturas minoritarias de su cada vez más pequeño y restringido ámbito local al mundo global de Internet es la gran distancia que separa estos pueblos de Internet, la denominada "Brecha Digital". Esta es definida por la Organización para la Cooperación y el Desarrollo Económico como "la diferencia entre individuos, hogares, negocios y áreas geográficas de niveles socio-económicos distintos en lo que se refiere a sus oportunidades de acceso a las tecnologías de la información y la comunicación (TIC) y a su uso de Internet para una amplia variedad de actividades"

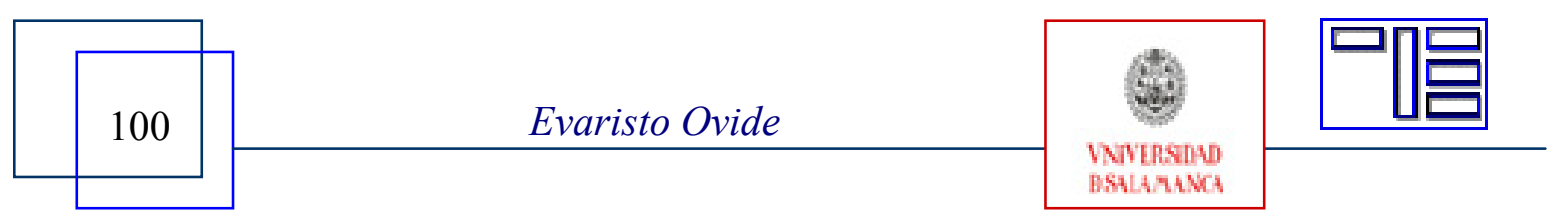


La primera causa de esta brecha digital en las culturas minoritarias es que la pérdida de su lengua y su identidad cultural suele ser el menor de sus males: desempleo, pobreza, falta de formación, marginación social y otros problemas similares suelen ser bastante más acuciantes. Esto hace que la existencia de ordenadores (conectados a Internet), el software necesario, el conocimiento de cómo usarlos y las oportunidades que les pueden brindar - piedras angulares de todo el proceso - sean los grandes ausentes. Teniendo en cuenta que, muchas veces, estas culturas están ubicadas en zonas rurales, la conexión a Internet puede ser un problema de difícil solución en estados de gran extensión donde las compañías telefónicas no tienen interés económico alguno en llegar y el gobierno no toma las medidas oportunas para asegurar ese servicio. Si además consideramos el hecho de que las lenguas y culturas amenazadas, por una serie de razones, suelen estar en países en vías de desarrollo donde incluso en las ciudades el acceso a Internet no es fácilmente asequible para el ciudadano medio, la dificultad del proyecto se agudiza.

Teniendo en cuenta estos factores, el uso de Internet tendrá que llevarse a cabo en telecentros o centros colaboradores como universidades o centros educativos. En etapas posteriores y con financiación para realizar una inversión en infraestructuras, se podrían crear redes inalámbricas para llevar Internet a pequeños municipios donde no haya otras posibilidades. En lugares sin teléfono (y donde no llegó el cable de cobre, no llegó tampoco el cable coaxial) esta es la única opción. En España se llevó a cabo con éxito un proyecto de estas características en la Campiña Sur cordobesa que permitió llevar Internet de banda ancha a zonas rurales que no eran de interés comercial para ninguna empresa de telecomunicaciones. ${ }^{8}$ En las etapas iniciales, sin embargo, estableciendo convenios con telecentros y centros educativos para poder usar Internet en sus instalaciones podría solucionar las necesidades del proyecto para ponerlo en marcha cuanto antes (hay lenguas cuya cuenta atrás está muy avanzada).

Por otro lado, el hecho de no tener conexión a Internet en nuestras casas o nuestra comunidad no implica que sea imposible desarrollar ninguna tarea con las NN.TT., ya que aun sin Internet, se pueden enseñar muchas cosas: edición y creación de sitios web, edición de vídeo, audio y fotografía, creación de bases de datos, textos, hojas de cálculo, presentaciones multimedia, digitalización de documentos gráficos u audiovisuales, etc. La necesidad de tener ordenadores será otro problema a solucionar, ya que la comunidad, precisamente por las circunstancias que la llevan a estar en peligro de extinción, no tendrá fondos para comprarlos. Este punto podría ser más fácil de solucionar que el del acceso a Internet, ya que los equipos necesarios para nuestros fines no son los que se venden en el mercado como estándar (desde un punto de vista europeo). Los ordenadores que se venden en el mercado tienen unas características técnicas que exceden con mucho las necesidades de la inmensa mayoría de los usuarios. Si el proyecto cuenta con un equipo de informáticos, se podrán adquirir ordenadores antiguos de segunda mano o procedentes de donaciones de centros escolares, universidades, etc para poder arreglarlos si es necesario y equiparlos con los necesario. Respecto a las licencias del sistema operativo y demás programas, usando software libre, además de obtener sistemas mucho más robustos y potentes, conseguiremos un ahorro del $100 \%$.

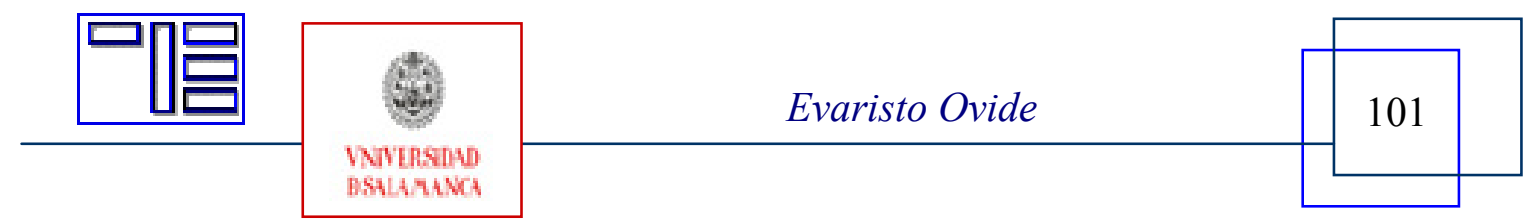


Revista Electrónica Teoría de la Educación.

Educación y Cultura en la Sociedad de la Información.

http://www.usal.es/teoriaeducacion

Vol. 9. No 2. Mayo 2008

Esto haría que la tarea de equipar con ordenadores la comunidad sea mucho más factible y realista que si se plantea comprar equipos nuevos.

Otra cuestión importante relacionada con la situación económica de estas culturas amenazadas (y normalmente socialmente discriminadas por la cultura dominante) es que muchos de sus problemas se solucionan, lamentablemente, renunciando a su cultura propia (lengua, tradiciones, ropas, costumbres, forma de vida, etc) e integrándose lo más plenamente posible en la cultura dominante, con las costumbres y demás características de la misma. De ahí que la solución para la recuperación de una lengua y su cultura pase a veces por superar una decisión intencional por parte de los miembros de la misma de renegar de ella y abandonarla con el propósito de mejorar su calidad de vida y su aceptación social. De ahí que un aspecto fundamental para la supervivencia de las lenguas es que formen parte activa y sean un factor rentable dentro del panorama político y económico, tanto por las visión que tendrán de sí mismos los hablantes como por las oportunidades que les brindará para su propia calidad de vida (Bernard, 1996).

\section{4.- METODOLOGÍA Y HERRAMIENTAS.}

Como comentábamos más arriba, los recursos disponibles para la recuperación de una lengua y cultura amenazada serán muy limitados (si fueran abundantes no estaría en ese estado), con lo que el planteamiento que seguimos en este artículo parte de esta base para la realización del proyecto. Un problema importarte tradicional en la recuperación de lenguas y culturas amenazadas era que hacían falta recursos muy considerables para poder llevar a cabo las tareas más fundamentales. Así, Fishman afirma que es crucial para la recuperación de una lengua minoritaria identificar las prioridades para "concentrar los mínimos recursos disponibles de la forma más juiciosa posible" (Fishman, 1990, p. 18). Afortunadamente, con la llegada de la Web 2.09, o Internet lecto-escritora (en oposición a los primeros años, donde el usurio medio solo podía leer o recibir contenidos y solo la minoría especialista podía crearlos), la Red se ha convertido en un espacio mucho más participativo donde el usuario ya no solo lee, sino que también crea, escribe, publica, exhibe, participa, opina y modifica los contenidos. Publicar contenidos de todo tipo (texto, audio, vídeo, imágenes, etc) en Internet es ahora una tarea fácil y gratuita al alcance del usuario, lo cual es una enorme ventaja cuando el presupuesto disponible es más que limitado.

A continuación describiremos los cinco grandes apartados que consideramos necesarios para poder invertir el proceso de extinción de una lengua y cultura amenazadas: Documentación, difusión, comunicación, formación y comercialización. Junto con estas cinco fases, indicaremos la forma en que las NN.TT. nos permitirán llevarlas a cabo con un presupuesto muy limitado. Los distintos pasos no son todos novedosos en sí, sino que la aportación en este artículo reside en la utilización de las NN.TT. para llevar a cabo las tareas que hasta ahora se venían realizando con otros medios de mucha menor eficacia y eficiencia.

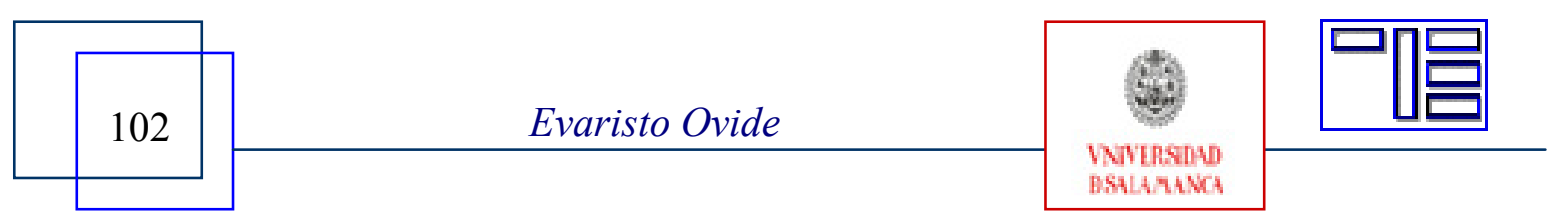


Fig. 1: Las grandes tareas en el proceso de recuperación de culturas amenazadas.

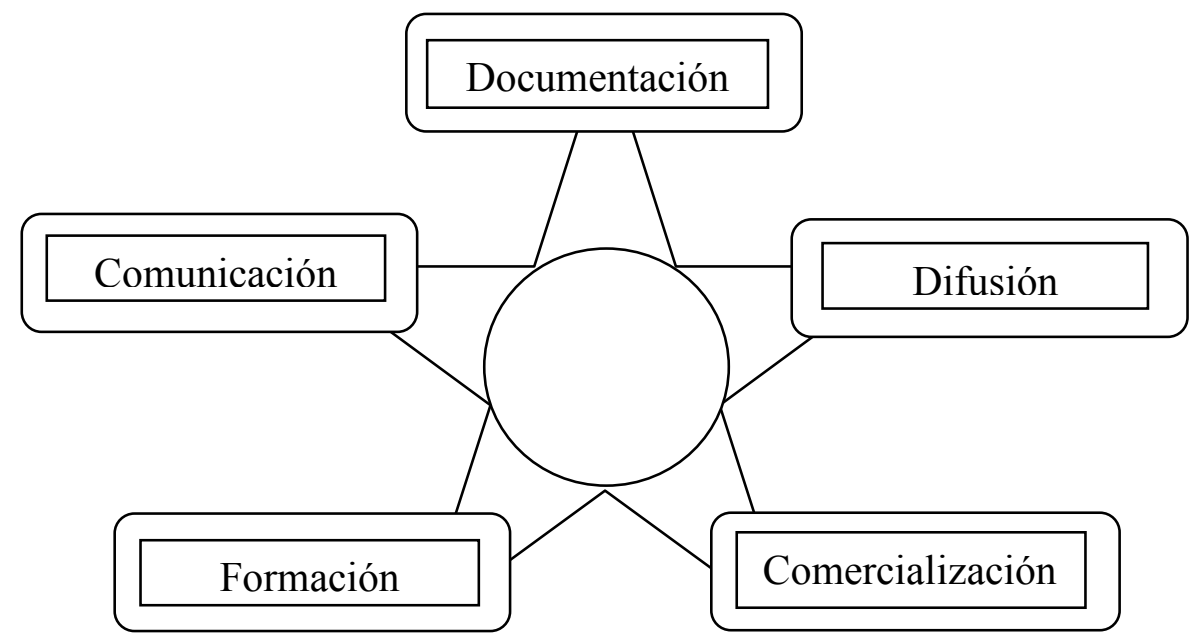

\subsection{Documentación:}

El primer paso cuando tratamos con culturas amenazadas debería ser documentarla en todas sus manifestaciones: lengua, fiestas, música, rituales, bailes. Puede ser que no podamos salvar la lengua por quedar solo hablantes mayores y no haber traspaso intergeneracional o que la cultura amenazada esté siendo asimilada a un paso mayor del que podamos contrarrestar o que los integrantes de la misma piensen que lo mejor para ellos es abandonar su lengua y su cultura por asociarla a un estadio cultural inferior, menos desarrollado, a una peor calidad de vida, a una marginación y discriminación social constante, o cualquier otra idea (con fundamento o sin él), pero si tenemos documentadas las manifestaciones culturales de un pueblo (y sobre todo su lengua), estas pueden revivirse, como fue el caso de la lengua hebrea en Israel, tras haber estado extinta durante siglos como lengua de comunicación.

Para llevar a cabo este trabajo de documentación pueden usarse grabadoras digitales para grabar voz, ya que tienen una capacidad de horas grabación, son muy ligeras y permiten una fácil introducción a un ordenador.

Para documentar la mayoría de los eventos, preferiremos realizar una grabación con vídeo para obtener la imagen además de la voz. Si el presupuesto no llega para una cámara de vídeo, una cámara de fotos con capacidad de vídeo nos servirá de momento para grabar bailes, ceremonias, entrevistas, creación de artesanía, etc. Hay que asegurarse de que la cámara no tenga más límite de grabación que la capacidad de la tarjeta de memoria, que debería ser de al menos 1GB (con una Kodak C360, por ejemplo, esa capacidad permitiría almacenar 1 hora de vídeo a tamaño 640 x 480 o 2 horas a tamaño 320 x 240). Una vez realizadas las grabaciones, se pasarán al ordenador, donde podrán editarse (dependiendo de en qué formato grabe nuestra cámara podremos

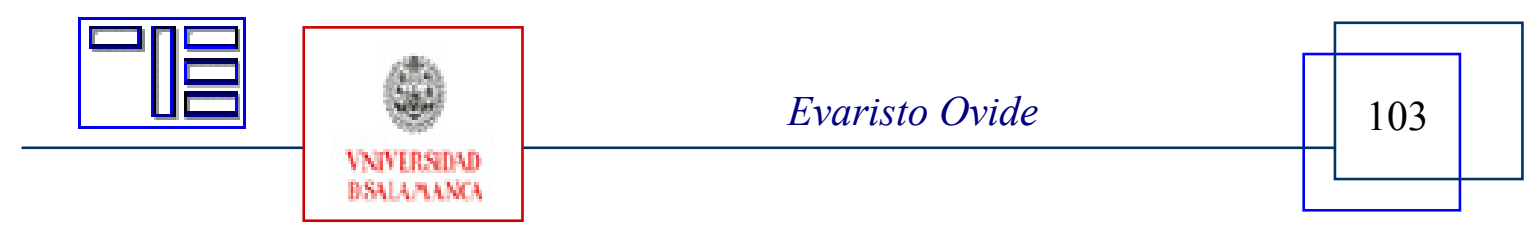


Revista Electrónica Teoría de la Educación.

Educación y Cultura en la Sociedad de la Información.

http://www.usal.es/teoriaeducacion

Vol. 9. No 2. Mayo 2008

necesitar varios programas de edición de vídeo, que encontraremos en Internet sin tener que pagar por ellos) y subirlos a algún sitio web para reproducirlos en streaming desde cualquier sitio web o blog que queramos.

Este proceso de documentación no consiste únicamente en la grabación de audio y vídeo de las representaciones culturales de una comunidad, sino que la grabación constituye la base para poder trabajar sobre ellas y llevar a cabo esta primera etapa de documentación. Así, la documentación de una lengua implica, sobre la base de los datos aportados por las grabaciones, elaborar una descripción de su sintaxis, morfología, fonología, pragmática y semántica, así como la identificación de las variedades geográficas o diatópicas, sociales o diastráticas y de registro o diafásicas. La documentación de un baile implica, sobre la base de los datos grabados, describir los distintos pasos, su coreografía, el número de participantes, su origen, sus variaciones, etc.

La enorme ventaja que presentan la utilización de las NN.TT. respecto a los métodos tradicionales es que hay una enorme reducción en los costos del procesos. Un miembro de la comunidad o una persona que viva cerca puede grabar una conversación y quizás entenderla y poder traducirla, pero solo el especialista podrá hacer hacer una transcripción fonética de la misma o describir la gramática de la lengua. Con la utilización de las NN.TT., se pueden enviar por Internet los archivos orales grabados para su posterior análisis en el país en el que esté el especialista. Cualquier duda o aclaración puede resolverse a través de programas de mensajería instantánea con voz, vídeo y texto totalmente gratuitos. El proceso de comunicación y envío de materiales a través de Internet permite que los lugares sean mucho más accesibles y que los especialistas ya no estén en lugares o países distantes desde los que llegar para ayudar requiere altos presupuestos.

\subsection{Difusión:}

Una vez tenemos documentada tanto la lengua como las manifestaciones culturales (o a la vez que lo vamos haciendo, según el método que estemos siguiendo), es fundamental publicar en Internet los datos para que el mundo sepa de la existencia de esta cultura y de su lengua. Nadie se preocupa por lo que no conoce y nadie echa de menos lo que desaparece si ni siquiera sabía que existía. De ahí que el esfuerzo de crear un corpus, tanto en la lengua propia como en la dominante (y en inglés si es que no es la dominante), sea fundamental para ocupar un lugar en el mundo de los que no viven en nuestra comunidad. Si no estamos en Internet, sencillamente no existiremos para la inmensa mayoría del mundo. Como afirma Grin, la imagen que la lengua proyecte al mundo es fundamental para su supervivencia: "La lengua minoritaria necesita tener una imagen suficientemente buena. Cualquier política lingüística que aporte dinero pero no se comprometa firmemente con impulsar la imagen pública de la lengua está condenada al fracaso. Parece que no puede ser de otra forma: para que una lengua sobreviva, su imagen tiene que ser positiva." (Grin, 1990, p. 71). Por lo tanto, no es suficiente con

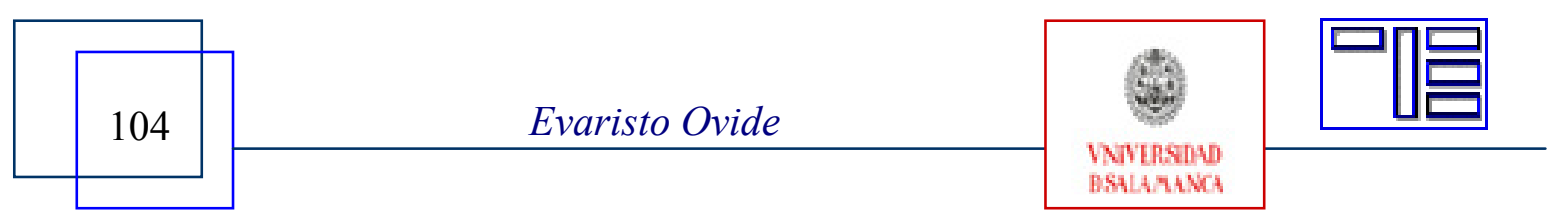


tener documentada la lengua y la cultura, creada la gramática, la ortografía y estudiada la cosmovisión de una comunidad: hay que transmitirla al mundo para que la conozcan, aprecien y respeten, y eso, hoy en día es una labor que las NN.TT. facilitan de forma considerable.

Es importante tener un sitio web para organizar las distintas partes del proyecto: televisión digital, archivos de audio, biblioteca digital, etc. Para este fin podemos recurrir a Google Page Creator, donde después de ingresar con nuestra cuenta de Gmail (si no la tenemos, vale la pena crear una, gratuita y con excelentes prestaciones), se nos ofrece un gran espacio para crear varios sitios web, cada uno con una dirección diferente del tipo http://nombredelsitio.googlepages.com y sin publicidad de ningún tipo (además, el espacio está limitado por cuenta de email, no por usuario). Incluye diseños preestablecidos que permiten hacer un sitio web con una apariencia muy profesional en cuestión de minutos.

Los blogs son plataformas muy convenientes para la creación simple de periódicos y revistas. Permiten seguir un orden cronólogico e interactuar a los lectores con sus opiniones acerca de lo que se va publicando. En los blogs se pueden incluir archivos de vídeo y audio. El sitio web que ofrece los blogs con más prestaciones y posibilidades actualmente es Blogger ${ }^{10}$ (también propiedad de Google).

Para difundir archivos orales (canciones, música, entrevistas...) recogidas en la etapa anterior, un excelente programa de edición de audio es Audacity ${ }^{11}$, software libre y gratuito (en caso de que queramos editar el archivo, añadir música a una entrevista, reducir el ruido, etc) y un sitio web donde podemos almacenar nuestros archivos de audio para reproducirlos en streaming desde cualquier sitio web o blog de forma totalmente gratuita puede ser Odeo ${ }^{12}$ o Gcast $^{13}$.

Los vídeos recogidos en la etapa anterior pueden ser difundidos a través de muchas plataformas, cada una con sus peculiaridades. Youtube ${ }^{14}$ es la más popular (propiedad de Google desde Octubre de 2006), si bien su calidad no es muy buena. Google Vídeos ${ }^{15}$ permite subir archivos de más de $100 \mathrm{MB}$ (límite de YouTube y muchos otros sitios web de este tipo) y además tiene un comienzo mucho menos distrayente que el de YouTube. Stage6, de la empresa Divx.com, permite tamaños de hasta 2 GB y en formato divx, con la enorme calidad que este ofrece. Hay muchas otras y tenemos que ver cuál nos dará un mejor servicio en función de las necesidades que tengamos (tamaño y duración de los vídeos, formato en que los vamos a grabar, posibilidad de habilitar RSS, etc). Vemos que aquí las posibilidades son enormes, ya que estas plataformas nos facilitan crear programas de televisión sin más coste que el tiempo que nos lleva grabarlos, editarlos y subirlos a la plataforma en cuestión, con la conversión de formatos que pueda ser necesaria. Si a estos vídeos les añadimos subtítulos, las posibilidades de una mayor audiencia y mayor presencia y fomento de la lengua propia aumentan considerablemente.

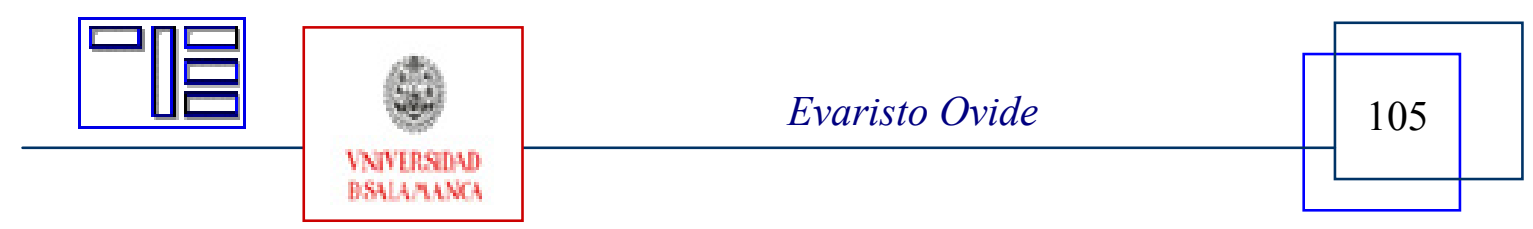


Revista Electrónica Teoría de la Educación.

Educación y Cultura en la Sociedad de la Información.

http://www.usal.es/teoriaeducacion

Vol. 9. No 2. Mayo 2008

\subsection{Comunicación:}

Los miembros de culturas amenazadas suelen estar dispersos por el Estado en un esfuerzo por buscar una forma de ganarse la vida cuando la cultura dominante les impide, de una forma u otra, seguir con su forma de vida tradicional. Así, su lengua y sus raíces se van perdiendo al integrarse en la cultura dominante y perder la comunicación con su gente, de forma que la tercera generación verá las costumbres y lengua que sus padres practicaron pero ya abandonaron hace tiempo como algo anecdótico que nada tiene que ver con ellos, que desde pequeños crecieron en un ambiente que poco tiene que ver con el de sus ancestros y en el que quizás nunca se les enseñó nada sobre sus raíces ni en la escuela ni quizás en casa. La creación de una comunidad online es lo que posibilita que se mantengan los lazos del grupo sin importar donde estén sus miembros y que pueda servir como centro social para poder seguir conociendo los problemas de la comunidad, seguir practicando la lengua aunque en el nuevo ambiente físico ya no haya miembros de su propia etnia, seguir participando en la vida del grupo a través de escritos, grabaciones de voz o de vídeo con webcam y, en resumidas cuentas, no perder el contacto con las raíces.

La ventaja de las comunidades virtuales es que permiten dos tipos de comunicación: sincrónica y asincrónica. Así, si queremos participar de forma asincrónica en la vida del grupo tenemos los foros, donde podemos dejar nuestra participación por escrito o en una grabación oral. Quizás sería conveniente dedicar alguna sección del foro para intervenciones en la lengua propia y otra para intervenciones en la dominante, de forma que se pueda garantizar la libertad de poder hablar la lengua propia sin prejuicios de ningún tipo ni obstáculos de cortesía.

Los blogs son otra herramienta que también se puede utilizar como medio de comunicación, ya que uno puede contar reflexiones personales, vivencias propias, hechos que vio, etc, sin ser propiamente una revista o periódico con intención de informar de hechos objetivos y los demás pueden opinar sobre lo que se escribe, poner un enlace a su propio blog y estrechar la comunidad de esa forma.

Por otro lado, tenemos la comunicación sincrónica. Mencionaremos aquí tres programas (gratuitos, como todos los recursos que aquí mencionamos) que permiten la comunicación a tiempo real con texto, voz y vídeo. Se mencionan los tres porque la calidad de cada forma de comunicación es distinta en cada uno. Así, Skype ${ }^{16}$ es el programa con mejor calidad de voz de los tres, permitiendo audioconferencias de hasta 9 miembros y con un programa accesorio, se puede incluso grabar la conversación (muy útil para entrevistas con personas lejanas sin tener que viajar); Yahoo Messenger ${ }^{17}$ permite una eficaz comunicación textual, incluso cuando la otra persona no está conectada y Windows Live Messenger ${ }^{18}$, el más popular, permite una muy buena comunicación por webcam. Sin embargo, estos programas están continuamente siendo mejorados y las ventajas entre ellos aquí mencionadas cambian con el tiempo según van mejorando sus servidores e infraestructuras.

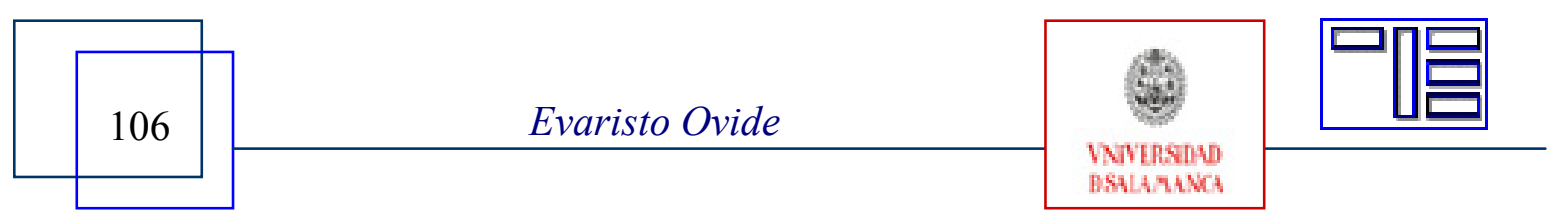




\subsection{Formación:}

La formación es el elemento necesario para transmitir los conocimientos ancestrales de esa cultura (lengua, valores, tradiciones, etc) junto con los conocimientos que necesitan para poder adaptar su cultura al mundo actual y defender esos valores en la sociedad actual (informática, inglés y la lengua dominante del lugar, entre otras). En este contexto hay que entender la formación bajo los dos puntos de vista (formar en conocimientos tradicionales y actuales), ya que excluir uno de los dos dejaría a los miembros de la comunidad anclados en un anacronismo y vulnerables ante una sociedad cuyas herramientas no conocen o bien los integraría en una cultura que no es la suya mientras pierden un valioso patrimonio cultural, histórico y lingüístico.

Un problema común es que en las comunidades originarias de los estudiantes no suelen ofrecerse todos los grados de educación (una excepción serían las comunidades urbanas, cuyo proceso de integración en la cultura dominante suele estar avanzado y el uso de la lengua suele ser mínimo, si es que aún alguien la conserva) y tras cursar la Educación Primaria en el lugar donde viven o muy cerca de él, la familia del estudiante se enfrenta a la difícil opción de enviarlo a una ciudad a seguir sus estudios o bien, si los medios económicos no alcanzan, interrumpir su educación. En el primer caso, el riesgo inminente es el de la integración del estudiante en la cultura dominante para tener mayor éxito social, especialmente a la edad en que empezaría la Educación Secundaria, siendo un adolescente. Pertenecer a una cultura minoritaria y amenazada casi siempre implica discriminación de algún tipo $\mathrm{y}$, sin contar con el respaldo de una comunidad y a una edad en que la integración social es tan importante, el proceso de asimilación en la cultura dominante y la pérdida de la propia (sobre todo la lengua, que es la primera víctima del desuso) es poco menos que inevitable, como podemos constatar en el mínimo y normalmente inexistente dominio lingüístico de su lengua tradicional de las comunidades de culturas minoritarias que viven en zonas urbanas (si bien estas tienen otras características, como ser las más activas en el movimiento político, tener mayor acceso a educación, medios de comunicación, quienes mejor conocen el sistema, con las ventajas que eso conlleva en la lucha por sus derechos).

La teleformación podría ser una solución efectiva en algunos casos para poder prestar una educación más allá de la básica sin tener que abandonar el hogar ni renunciar a la educación ni a la cultura propia. Como mencionamos en el punto 3, equipar una sala con algunos ordenadores no supone un costo muy grande. Si se puede habilitar una conexión a Internet, los estudiantes podrían recibir y enviar tanto materiales de estudio a la vez que se pueden comunicar con profesores y compañeros. En el peor de los casos, en que Internet no estuviera disponible en ciertas comunidades donde ni siquiera hay teléfono (pensemos en lugares del interior en Argentina, donde se pueden recorrer cientos de kms sin ver un solo pueblo), una educación a distancia como se hacía antes por correo podría llevarse a cabo enviando cds o dvds en vez de libros, lo cual tendría un costo mínimo y los estudiantes podría tener acceso a vídeos, grabaciones de sus profesores, ejercicios, textos, etc digitales. El uso de la emisora y el receptor de radio,

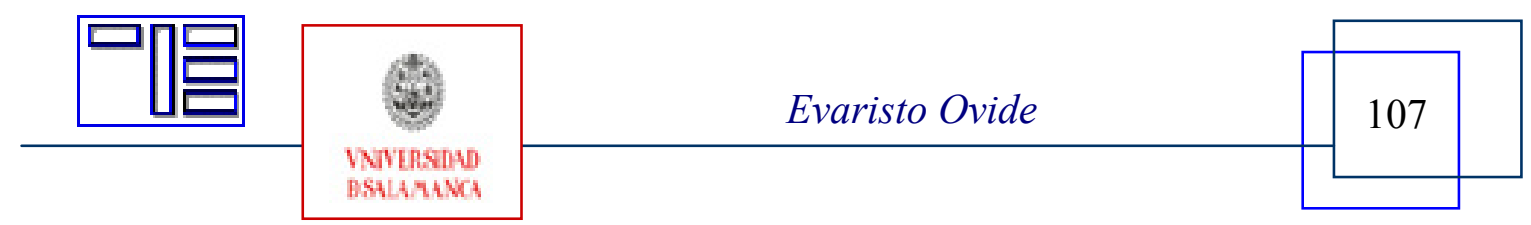


Revista Electrónica Teoría de la Educación.

Educación y Cultura en la Sociedad de la Información.

http://www.usal.es/teoriaeducacion

Vol. 9. No 2. Mayo 2008

difícilmente considerables como NN.TT. hoy en día, pueden ser en estos casos, en los que otras infraestructuras más modernas no están disponibles, posibles soluciones eficaces para complementar esa educación a distancia con formas de comunicación oral entre los participantes del proceso educativo.

Cuando contamos con Internet y queremos montar un servidor donde los estudiantes y profesores puedan comunicarse e intercambiar documentos y ejercicios en ese espacio virtual, tendremos como grandes aliados de nuestro pequeño presupuesto a los sistemas operativos de software libre y gratuitos, como GNU-Linux (en sus distintas distribuciones) o plataformas educativas como Moodle ${ }^{19}$, Dokeos ${ }^{20}$ o Atutor ${ }^{21}$, junto con otros muchos programas también de software libre, gratuitos y mucho más robustos y flexibles que las alternativas de pago.

Otro problema que afecta a las culturas amenazadas es que el sistema educativo del Estado donde se encuentran normalmente apenas presta atención a la cultura de la que proviene el estudiante, ni a su lengua nativa, por lo que puede estar siendo educado en una lengua que no expresa el mundo como él lo ve (la lengua dominante) y con unos contenidos que dan una visión de la historia de su pueblo distinta a la que cuentan sus abuelos (la visión del colonizador-invasor-conquistador). Normalmente, una cultura amenazada cuenta con muy poca influencia para poder cambiar el currículum educativo impuesto por un Estado, ya que eso implica que el Estado reconozca el punto de vista de los invadidos, colonizados o discriminados, su historia, su lengua y, en cierto modo, dar legitimidad a sus reclamaciones políticas, con lo que los pasos en este sentido por parte del Estado siempre serán tímidos y lentos.

Las NN.TT. también pueden ayudar a solucionar este problema. La facilidad con que se puede establecer un sistema educativo online permite la posibilidad de transmitir unos contenidos a un gran número de destinatarios. Las plataformas mencionadas más arriba nos permiten tener un apoyo a las clases tradicionales del sistema educativo estatal, pero también permiten crear un sistema educativo complementario donde enseñar los contenidos que el Estado se niega a difundir y que más afectan a la visión que el propio estudiante tiene de su propia cultura y historia y también contenidos para aquellos que ya no tienen lugar en las aulas de educación reglada, como puede ser enseñanza para adultos.

Por otro lado, la enseñanza a través de Internet también permite expandir los conocimientos de la propia cultura para que sea conocida y aprendida en círculos más amplios que el de nuestra propia comunidad. Esta es una forma de presentarse al mundo y permitir que se conozca una cosmovisión, una lengua, unas tradiciones que enriquecerán el patrimonio mundial y podrán aumentar el número de hablantes y simpatizantes, siempre necesarios en la dura lucha por la supervivencia como cultura amenazada.

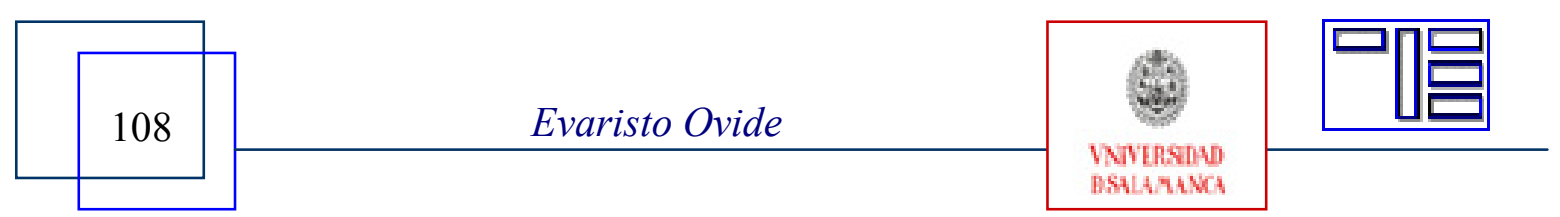




\subsection{Comercialización}

Cooper (Cooper, 1989) plantea el proceso de planificación lingüística en términos de marketing: un producto (la lengua), un grupo a quien orientar el producto (potenciales hablantes), una promoción adecuada del producto, un lugar donde comprar el producto (existencia de gramáticas, diccionarios, etc), precio adecuado (el esfuerzo de aprender la lengua o ajustarse a la norma académica tiene que ser menor que el beneficio que reporta). Es un planteamiento de trabajo muy detallado con el que estamos muy de acuerdo por dos razones principales: en primer lugar, porque implica una forma de trabajo muy bien fundamentada y documentada, y por tanto, con muchas más probabilidades de éxito. En segundo lugar, porque convencer a una comunidad para no dejar de hablar su lengua, vestir sus ropas tradicionales y no abandonar sus viejas tradiciones implica una campaña de marketing propiamente dicha que bien podría equipararse a la de intentar convencerlos para que usen esta o aquella marca de perfume, ropa, coche, etc. De hecho, incluso donde no hay ningún obstáculo legal ni de otro tipo para que las culturas originarias del lugar lleven sus ropas tradicionales, lo más jóvenes rápidamente las abandonan para integrarse en una forma de vestir que las campañas de marketing televisivas, en revistas y demás medios de comunicación les han convencido de que es más moderno, mejor y con la que se van a tener un gran éxito social (sobre todo, si creemos al anuncio, con el sexo opuesto). Puesto que el marketing es un elemento que trabaja en contra de las culturas minoritarias de forma tan eficaz, parece muy aconsejable utilizar esos mismos principios para contrarrestar sus efectos.

Yendo más allá del planteamiento de Cooper, creemos que hay que llevar un paso más allá la aplicar estos principios del marketing para campañas no empresariales para llegar a hablar de marketing en situaciones empresariales y no solo como unos principios aplicados a la sociolingüística o a la antropología social. Si una lengua y su cultura implican pobreza, marginación social y desempleo, sus miembros acabarán por renunciar a ella para buscar una mejor calidad de vida (lo cual es bastante comprensible) y la lengua morirá. Para sobrevivir, una cultura tiene que ser rentable o sus miembros la abandonarán irremediablemente en pocas generaciones atraídos por la mejor calidad de vida de la cultura dominante que les deja pocas opciones para las subsistencia digna.

Las formas tradicionales de subsistencia tales como venta de artesanías, pinturas, ropas $\mathrm{u}$ otros tejidos, etc podrían promocionarse en sitios web donde cada artículo estuviera fotografiado y detallado, de forma que se pudieran vender los artículos a clientes y/o a comercios o almacenes de ciudades.

Las zonas rurales donde tradicionalmente vivieron y que tan bien conocen podrían anunciarse en páginas web y utilizarse para el alojamiento de turistas, donde se les ofrecería también comidas típicas de la zona, así como muestras culturales de distintos tipos (bailes, cantos u otras), actividades como senderismo con guía, talleres de artesanía, etc. Esto no solo mejoraría la economía de la comunidad, sino que también acercaría la cultura en cuestión a la gente de fuera de ella.

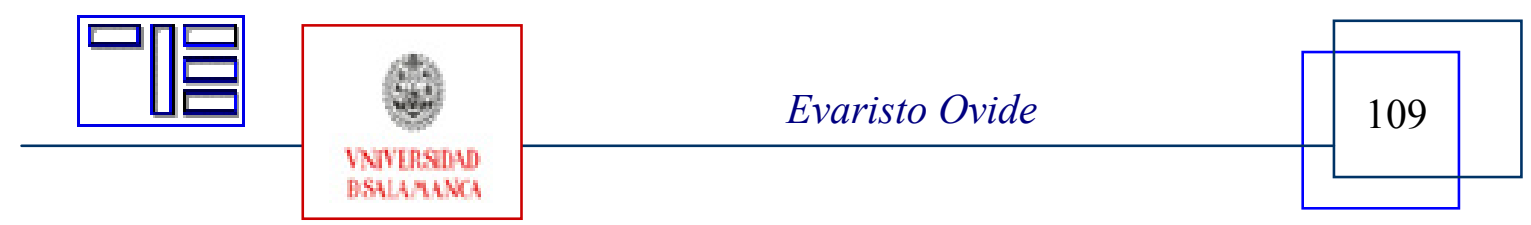


Revista Electrónica Teoría de la Educación.

Educación y Cultura en la Sociedad de la Información.

http://www.usal.es/teoriaeducacion

Vol. 9. No 2. Mayo 2008

Aparte de estas actividades, hay otras que podríamos denominar más intelectuales, como la impartición de cursos de lengua propia o la publicación de libros, que a través de sitios web como lulu.com ${ }^{22}$ permiten vender libros encuadernados, así como calendarios y otros elementos de papelería sin necesitar una imprenta.

Obviamente, para que la gente conozca el valor de las artesanías de una comunidad X, hay que promocionarla. Para que los lingüistas y las universidades conozcan los cursos de lengua autóctona, hay que comunicarlo. Todo esta labor de marketing se puede hacer a través del email y de Internet de forma gratuita.

\section{5.- CONCLUSIONES.}

A lo largo de estas líneas hemos intentando mostrar el valor de las lenguas y culturas amenazas y lo mucho que se pierde cuando una desaparece así como las grandes oportunidades que brindan las NN.TT. para conservarlas y promocionarlas de una forma que no se podría haber imaginado antes de la llegada de Internet. Si bien es cierto que la introducción de Internet trajo una discriminación más entre ricos y pobres, la de quién tiene acceso a la información y quién no (la llamada "Brecha Digital"), no es menos cierto que también trajo una oportunidad para que todos tengan una voz libre en el mundo.

Hemos descrito de forma general los cinco grandes apartados que consideramos necesarios para un proyecto de estas características. Es evidente que el proyecto es mucho más complejo que lo que se ha descrito aquí y que cada uno de esos apartados tendría una extensión superior a este artículo. Por poner un ejemplo, el proceso de análisis y documentación de una lengua no se reduce a grabar a hablantes de la misma, sino que hay un largo y tedioso trabajo para identificar isoglosas, sociolectos, dialectos, fonemas, tonemas, etc... Por otro lado, las etapas descritas aquí digamos que son las necesarias para recuperar la lengua y fomentarla desde dentro del grupo en cuestión. Sobra decir que es fundamental la actuación del gobierno en el que se encuentren para facilitar un marco legal en el que haya financiación, educación sobre y en la lengua propia, así como una política lingüística y cultural apropiada. Cuando el estado lleva a cabo una política represiva, las cosas son mucho más difíciles.

Sin embargo, aún a riesgo de haber simplificado en exceso las distintas etapas del proyecto, creemos que esta aplicación de las NTTT sirve para mostrar el doble papel de Internet: por un lado aumentando la discriminación entre ricos y pobres con la llamada "Brecha Digital" y por otro, eliminando precisamente esas barreras y permitiendo que hasta los pobres puedan hacer que se oiga su voz en todo el mundo gracias a la gratuidad de servicios de publicación y almacenamiento en Internet que llegó con la Web 2.0, cuando el usuario tomó las riendas de Internet dejando de ser un sujeto pasivo que solo consumía contenidos y pasando a ser productor de los mismos. Podríamos decir que Internet es como un tren que tiene muy pocas paradas en los sitios pobres,

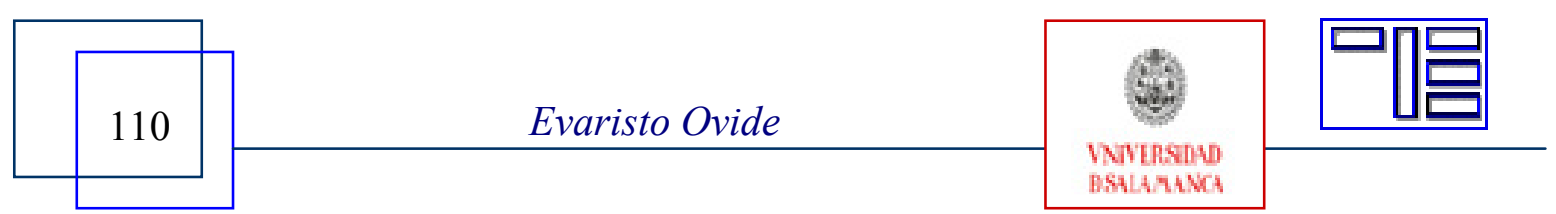


pero en el que todos los pasajeros que logran subirse, ricos o pobres, viajan en los mismos asientos.

\section{6.- BIBLIOGRAFÍA}

BERNARD, H.R. (1996). Language Preservation and Publishing. In: N. H. Hornberger, Indigenous Literacies in the Americas: Language Planning from the Bottom up. Berlin: Mouton de Gruyter, 139-156.

COOPER, R.L. (1989). Language planning and social change. Sydney, Australia: Cambridge University.

CRYSTAL, D. (2000). This man is worth $£ 100,000$ a year. High Life (British Airways):104-8.

CRYSTAL, D.(2006). Diversity? We ain't seen nothin' yet. Comunicación para la Fédération Internationale des Professeurs de Langues Vivantes. Conferencia: 'Diversity in Language Learning and Teaching', Gotemburgo, Suecia.

CUMBRE MUNDIAL SOBRE LA SOCIEDAD DE LA INFORMACIÓN (2004). Declaración de Principios de Ginebra. WSIS-03/GENEVA/DOC/0004. Consultado el 11 de enero de 2008 en: http://www.itu.int/wsis/documents/doc_multi.asp?lang=es\&id=1161|0

FISHMAN, J.A. (1990). What is reversing language shift (RLS) and how can it succeed? Journal of Multilingual and Multicultural Development, 11(1), 5-36.

GORDON, R.G., Jr. (ed.) (2005). Ethnologue: Languages of the World, Fifteenth edition. Dallas, Tex.: SIL International. Consultado el 12 de diciembre de 2008 en: http://www.ethnologue.com/

GRIN, F. (1990). The economic approach to minority languages. Journal of Multilingual and Multicultural Development, 11(1), 153-73.

UNESCO (2003). Language Vitality and Endangerment. Consultado el 10 de enero de 2008 en:

http://portal.unesco.org/culture/en/ev.phpURL_ID=9105\&URL_DO=DO_TO

PIC\&URL_SECTION=201.html

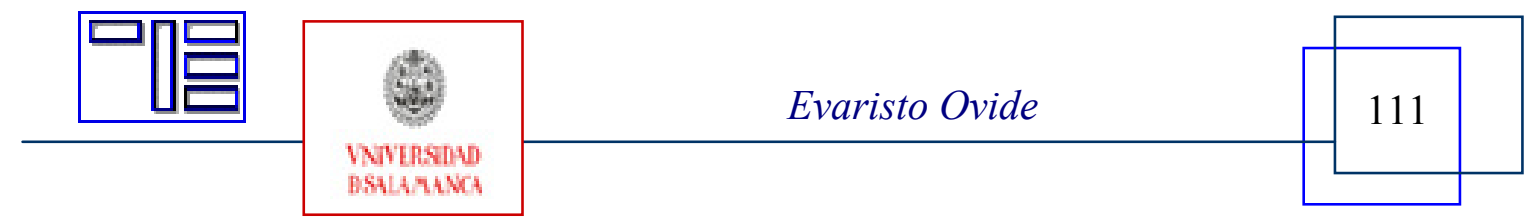


Revista Electrónica Teoría de la Educación.

Educación y Cultura en la Sociedad de la Información.

http://www.usal.es/teoriaeducacion

Vol. 9. No 2. Mayo 2008

\section{Notas:}

1. http://www.todoscontraelcanon.es/

2. Ver la Free Software Foundation en http://www.fsf.org

3. http://www.wikipedia.org/

4. Unesco Red Book of Endangered Languages:

http://www.tooyoo.l.u-tokyo.ac.jp/Redbook/index.html

5. Véase como ejemplo la inadecuación de la lengua castellana para describir las estaciones climáticas en colonias donde no había cuatro ni tenían las mismas características que en España, como Colombia, por ejemplo.

6. En Irlanda hay una ciudad llamada "Ardee", en el Condado de Louth, cuyo nombre original en gaélico es "Baile Átha Fhirdhia" ("El Fuerte de Ferdia"). En la plaza del pueblo hay una estatua de un guerrero llevando en brazos a otro moribundo. Sustituir "Baile Átha Fhirdhia" por "Ardee" implica eliminar completamente una referencia a la historia de un personaje mitológico bien conocido en la leyenda irlandesa como es Cuchulaim y su batalla con su amigo Ferdia, engañado por la reina Maeve. Es un claro ejemplo de cómo la sustitución de una lengua por otra, además de una pérdida lingüística, supone la pérdida de una gran riqueza cultural.

7.Organización para la Cooperación y el Desarrollo Económico:

http://stats.oecd.org/glossary/detail.asp?ID=4719

8. http://www.equal.red-

adeco.com/portal/intranova/PortalRedAdeco/Principal.nsf/VCCN01/8191473349?OpenDocument\&idiom $\mathrm{a}=1 \& \& \mathrm{px}=3$

9. http://www.web2con.com/web2con/

10. https://www.blogger.com/start

11. http://audacity.sourceforge.net/

12. http://odeo.com/

13. http://www.gcast.com/

14. http://www.youtube.com/

15. http://video.google.com/

16. http://www.skype.com/intl/es/

17. http://messenger.yahoo.com/

18. http://get.live.com/messenger/overview

19. http://moodle.org/

20. http://www.dokeos.com/

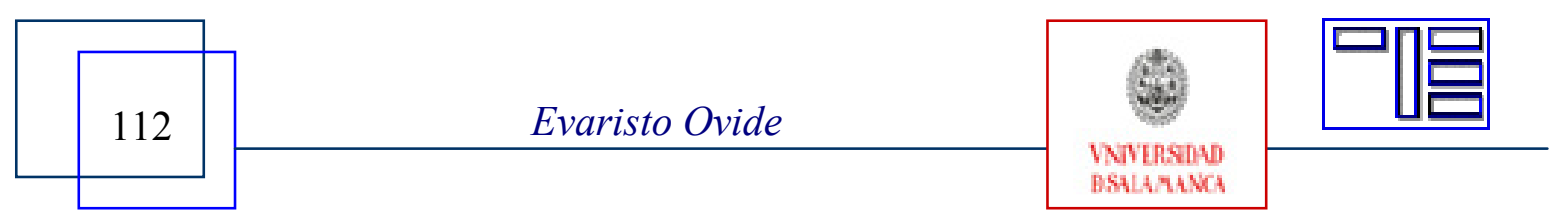


21. http://www.atutor.ca/

22. http://www.lulu.com

Para citar este artículo puede utilizar la siguiente referencia:

OVIDE, Evaristo (2008). Las TIC y las culturas minoritarias en un mundo global. En APARICIO, Pablo (Coord.) Desde la diversidad hacia la desigualdad: ¿destino inexorable de la globalización? [monográfico en línea]. Revista Electrónica Teoría de la Educación: Educación y Cultura en la Sociedad de la Información. Vol. 9, n 2. Universidad de Salamanca. [Fecha de consulta: dd/mm/aaaa]. $<\mathrm{http} / / /$ www.usal.es/ teoriaeducacion/rev_numero_09_02/n9_02_ovide.pdf $>$ ISSN 1138-9737

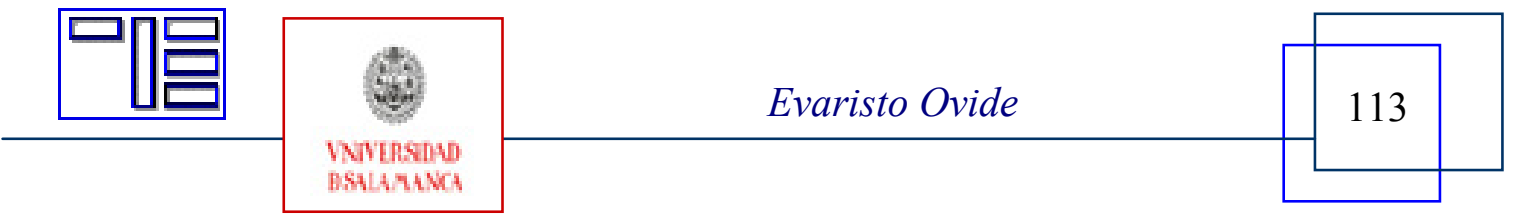

